\title{
A abordagem deflacionista da verdade: entrelaces entre Freud e Rorty
}

\author{
The deflacionary approach of truth: \\ intertwining between Freud and Rorty
}

Caio Menezes Tavares ${ }^{1}$

\section{Resumo}

A categoria "verdade" é um dos interesses do filósofo Richard Rorty. Ela pode ser relacionada à noção de "realidade psíquica" em Freud, categoria chave na formulação psicanalítica. Em ambos os autores, há uma concepção de verdade deflacionada. Eles recusam a existência de uma verdade absoluta e objetiva, dotada de uma essência oculta a ser revelada, segundo o projeto cartesiano; pelo contrário, assumem o argumento de que a verdade é construção (Freud), entidade linguística (Rorty). Para ambos, não há possibilidade para o ser de linguagem atingir o mundo real: sua experiência é mediada pela linguagem. Rorty abandona a concepção de "natureza intrínseca" do humano, explorando a contingência da linguagem. Freud problematiza a questão da realidade, no tênue limite entre realidade material e realidade psíquica, esta última apontando para a verdade do sujeito. Nesse sentido, não há verdade revelada do exterior, mas verdade do sujeito, na sua dimensão idiossincrática.

Palavras-chave: Verdade. Abordagem deflacionista. Psicanálise. Richard Rorty. Sigmund Freud.

\section{Abstract}

The category "Truth" is one of the philosopher Richard Rorty's interests. It can be related to Freud's "psychic reality", a key category in psychoanalytic formulation. In both authors, there is a conception of deflated truth. They refuse the existence of an absolute and objective truth, endowed with a hidden essence to be revealed, according to the cartesian model; otherwise, they assume the argument that truth is a construction (Freud), a linguistic entity (Rorty). For both, there is no possibility to the language being to reach to the real world: his experience is mediated by language. Rorty leaves the concept of "intrinsic nature" of human being, exploring the contingency of language. Freud problematizes the issue of reality, in the tenuous border between material and psychic reality, this one pointing to subject's truth. In this sense, there is no revealed truth from the outside, but subject's truth in his idiosyncratic dimension.

Keywords: Truth. Deflacionary approach. Psychoanalysis. Richard Rorty. Sigmund Freud.

Esta obra foi licenciada com uma Licença Creative Commons - Atribuição 3.0 Não Adaptada.

\footnotetext{
${ }^{1}$ Universidade Federal da Bahia. E-mail: caiomt@gmail.com

Cad. de Pesq. Interdisc. em Ci-s. Hum-s. Florianópolis, Santa Catarina, Brasil, ISSN 1984-8951 v.14, n.105, p.50-64, ago/dez 2013
} 


\title{
1 A deflação da verdade
}

\begin{abstract}
Dizer que deveríamos abandonar a ideia de uma verdade que se encontra diante de nós à espera de ser descoberta não é dizer que descobrimos que, diante de nós, não há qualquer verdade. É dizer que a melhor maneira de servir os nossos fins seria deixar de ver a verdade como um assunto profundo, como matéria de interesse filosófico, e de ver "verdadeiro" como um termo que merece "análise" (RORTY, 1992, p. 29).
\end{abstract}

O tema da verdade persistiu ao longo da história como um dos cernes de grandes debates filosóficos, e foi fruto da construção de diversas teorias. Um dos estudiosos que se ocupam do estudo das implicações deste termo é o filósofo Richard Rorty (1931-2007), célebre representante do chamado neopragmatismo e um dos expoentes do deflacionismo/abordagem deflacionista da verdade, mais especificamente em sua obra Contingência, ironia e solidariedade (1992). Rorty desenvolve, no livro em questão, uma série de questionamentos sobre a verdade. O autor recusa a ideia de uma verdade absoluta, completa, objetiva e passível de ser revelada.

Essa temática também pode ser extraída da obra de Sigmund Freud (18561939), partindo do pressuposto que sua categoria de "Realidade Psíquica" pode ser relacionada com a concepção de verdade em Rorty. A partir desse cotejamento, é possível propor uma aproximação entre as duas perspectivas, considerando que ambas evidenciam uma abordagem deflacionista, portanto, anti-metafísica do termo. Em parte de sua obra, Freud expõe sua noção de "realidade", sobretudo quando distingue realidade material de realidade psíquica, introduzindo esta última como categoria chave na formulação psicanalítica.

A abordagem deflacionista, como o nome indica, trata da "deflação" da verdade, confrontando teorias que se propõem detentoras da verdade única, como o modelo cartesiano, por exemplo. Rorty sugere o tratamento de uma verdade menos "inchada", "inflada", passando a enxergá-la com menor importância, menor valor e, sobretudo, sem uma essência, uma natureza intrínseca.

Tal perspectiva nos convoca a pensar se o próprio saber científico pode explicar a totalidade da realidade, se pode desvelar o real absoluto. Rorty se apoia em Nietzsche como uma das referências para seus questionamentos sobre a verdade. Segundo Ghiraldelli Júnior (1999), Nietzsche faz uma das mais importantes 
perguntas da história da filosofia ocidental: "Por que sempre a verdade?". A estrutura sobre a qual se desenvolveu a ciência até o século XIX, dentro dos pressupostos de previsão e controle dos fenômenos, objetivava o alcance da verdade, por meio do método universal, como proposto por Descartes no século XVII (DESCARTES, 1637/1983). O projeto cartesiano consistia em buscar formular critérios para um sujeito do conhecimento puro, depurado das suas dúvidas, paixões, ilusões e desejos, e capaz de alcançar a realidade de forma neutra, apontando para a certeza e a valorização das evidências, por isso a necessidade de um método único e universal. Alguns teóricos, como Nietzsche e, posteriormente, Rorty, questionam essa perspectiva, criticando o modelo de sujeito epistêmico cartesiano, "senhor" da sua razão e da sua consciência.

No texto de Rorty, percebe-se o quanto ele minimiza a ideia de que a verdade deve ser tratada como "assunto profundo" ou "material de interesse filosófico", pois acredita que a busca por uma natureza da verdade não é proveitosa. Ele retoma a argumentação nietzscheana da impossibilidade do "conhecimento da verdade", abandonando a tradicional noção que se tinha sobre a categoria.

Dizer que deveríamos abandonar a ideia de uma verdade que se encontra diante de nós à espera de ser descoberta não é dizer que descobrimos que, diante de nós, não há qualquer verdade (RORTY, 1992, p. 29).

$\mathrm{Na}$ abordagem do filósofo, não é a verdade que deixa de existir como categoria de estudo, mas o olhar que lançamos sobre ela é que deve ser reformulado. Rorty (1992) retoma uma posição que se estabeleceu desde o século XIX, quando artistas, e em particular os poetas românticos, reclamavam para a arte o mesmo lugar na cultura tradicionalmente ocupado pela religião e pela filosofia, da mesma forma que o lluminismo reclamou este lugar para a ciência.

Esses artistas buscavam romper, tanto com a hegemonia da ciência sobre as demais formas de conhecimento, quanto questionavam a necessidade de um método científico universal, como propunha Descartes (DESCARTES, 1637/1983). Uma das consequências desse questionamento é refletir de forma crítica sobre o tradicional modelo de cientificidade e seus preceitos de rigorosidade, universalidade e neutralidade em métodos, objetos e objetivos. Alguns filósofos, juntamente com outros grupos destacados por Rorty, como políticos utópicos e artistas inovadores, 
opuseram-se à suposta supremacia das ciências, classificando-a como apenas uma atividade humana e não o único paradigma revelador do real.

Crítico das cisões que a filosofia sofreu, ao separar o mundo dos fenômenos e da ciência empírica, do mundo da mente, do espírito e da natureza intrínseca humana, Rorty traz à tona o debate sobre se a verdade pode ser produzida ou descoberta. Segundo ele, foram os filósofos idealistas alemães, com destaque para Kant e Hegel, que separaram a chamada "verdade inferior", do mundo dos fenômenos, da "verdade superior", da mente e do eu essencial, domínio da filosofia.

Rorty desfaz essa separação, ao afirmar que a verdade não pode existir apartada da mente humana. Não podemos conceber a verdade sobre os fenômenos fora do âmbito da linguagem. A verdade é fruto da constante invenção humana, expressa por meio da linguagem. Ela não está diante de nós como um objeto sólido e essencial que contemplamos, mas ela nos habita. Rorty (1992, p.25) afirma:

dizer que a verdade não está diante de nós é simplesmente dizer que onde não há frases não há verdade, que as frases são elementos das linguagens humanas e que as linguagens humanas são criações do homem.

Uma das soluções do impasse criado pelos idealistas, para Rorty, é assumir que existe de fato um mundo diante de nós, onde certas coisas que existem no plano espaço-temporal independem dos estados mentais humanos. São os humanos que se apropriam das representações dessas coisas, ao descreverem-nas como verdadeiras ou falsas. É impossível, portanto, que o mundo tenha uma linguagem própria. "O mundo não fala; só nós é que falamos” (RORTY, 1992 p. 26). São os humanos autores de jogos de linguagem que estabelecem critérios para descrever o mundo e os próprios aspectos da vida humana, a política, a moral, etc. Segundo D’Agord, Binkowski e Chittoni (2008, p. 51):

Os jogos de linguagem trabalham na perspectiva de que não há uma essência enquanto dado natural, mas que o ser acontece em um horizonte de linguagem, isto é, em que os sentidos prévios e a produção de sentido exercem efeitos um sobre o outro.

A ordem da linguagem representa, portanto, uma peça chave para a compreensão da dinâmica de funcionamento da vida humana. Ela se afasta da ideia de natureza essencial, apontando para a construção e reconstrução de sentido, 
sempre em uma perspectiva a posteriori. Desse modo, Rorty, ao criticar a essencialização da verdade, sintetiza a sua concepção sobre ela: é construção de linguagem, concebida como entidade linguística, retomando a suposição de que a verdade é feita, e não descoberta. Como afirma Pinto (2007), ao referir-se ao argumento de Rorty, a verdade não pode estar "fora" da linguagem, pois uma crença, pertencente à linguagem, só pode ser justificada por meio de outra crença, igualmente vinculada à linguagem.

A teoria de Rorty é criticada por alguns de seus contemporâneos. Ghiraldelli Júnior (1999) faz referência ao filósofo John Searle que, dentre outros aspectos, discorda de que a verdade não é descoberta. Searle concorda com o fato de que, sendo as verdades declarações linguísticas, elas são fabricadas pelos humanos. Porém, quando essas declarações são consideradas verdadeiras, é o estatuto de verdade delas que é descoberto. Ou seja, o fato de essas declarações serem verdadeiras ou falsas é que seria descoberto. Ghiraldelli Júnior (1999) atenta para a crítica de Searle, e a considera um dos pontos cruciais para o debate realismo versus antirrealismo, acrescentando que, contrariamente ao que fora afirmado, Rorty buscava abandonar a dualidade fabricar/descobrir.

O embate entre as concepções de Rorty e Searle pode ser resumido na crença deste último, na existência de uma verdade independente de declarações linguísticas e, portanto, das representações humanas, atestando a existência de um mundo "lá fora", uma realidade externa. O argumento de Rorty, destacado por Ghiraldelli Júnior (1999), é que, de fato, existe uma realidade antes de falarmos dela, ou seja, ela é independente das declarações linguísticas do ponto de vista causal. No entanto, não podemos falar em independência representacional, já que não podemos tratar, por exemplo, dos objetos, fora dos nossos jogos de linguagem, em uma esfera além de todas as possíveis descrições. São eles que sustentam uma rede de relações "aberta e infinitamente expansível" (POGREBINSCHI, 2006, p.133), que os objetos mantêm entre si e com as pessoas, atestando a presença invariável da linguagem. 


\section{A subjetividade na interface das contingências}

As implicações da teoria de Rorty sobre a verdade se estendem para a própria noção de subjetividade. Seguindo o princípio de desessencialização da verdade, Rorty defende que o "eu" também não possui essência, natureza intrínseca ou materialidade, mas constitui uma rede de crenças e desejos, fruto da linguagem. Nesse sentido, a ideia de sujeito, em Rorty, passa a ser tratada como uma realidade linguística, dependente de contextos históricos contingentes.

Rorty resgata um amplo debate sobre a existência a partir da perspectiva de uma oposição entre universalidade e individualidade. A filosofia, especificamente anterior a Nietzsche, buscava encontrar a marca universal em todos os humanos, "as condições universais da existência humana, as grandes continuidades - o contexto permanente e a-histórico da vida humana" (GHIRALDELLI JÚNIOR, 1999, p. 51). Por outro lado, os filósofos pós-nietzscheanos, bem como os poetas, insiste Rorty, buscaram enxergar as contingências particulares que tecem o "eu" de cada um, o que é individual e distintivo em cada um de nós e nos permite alcançar a autocriação, a reinvenção de nós mesmos ao longo do tempo. Nessa nova concepção, é importante destacar a universalidade, bem como o singular e o contingente.

A marca universal da qual nos fala Rorty, na perspectiva dos filósofos prénietzscheanos, seria necessária e essencial, opondo-se ao que ele defende como sendo contingente. Não haveria, portanto, segundo ele, algo que determinasse a natureza humana, mas, sim, contingências particulares e seus contextos, o que pode ser visto como acidental, conjunto de vicissitudes e não essência. A novidade que Rorty ressalta da teoria de Nietzsche é que nosso autoconhecimento é uma autocriação, um confronto com nossas contingências, que nos permite criar linguagens próprias e não apenas reproduzir linguagens deixadas pelos outros. Novamente, retomando o papel de destaque dos poetas, de uma forma bela, Rorty diz que o maior medo deles é vivermos em um mundo herdado e sermos cópias, réplicas, ao invés de reinventarmos nossa própria linguagem.

Falar de um "eu verdadeiro" ou da verdade em si, para Rorty, é evocar uma imagem de Nietzsche, de que a verdade seria um "exército móvel de metáforas", ou seja, algo que está fora de uma representação unívoca pela linguagem, mas uma 
série de descrições contextuais. Exercitar metáforas seria o equivalente a renovar os jogos de linguagem costumeiros, constituindo novas crenças. Segundo Pinto (2007), o choque produzido pelas metáforas nos leva a re-tecer os padrões de nossas crenças e assim podermos usá-las ao lidar com as coisas ao nosso redor.

Ao contextualizar a verdade como construção, Rorty evoca o pensamento Freudiano. Ele lê Freud baseando-se no que há de contingente em elementos de sua obra: o "eu" é nada mais do que um "tecido de contingências e não um sistema de faculdades pelo menos potencialmente bem ordenado" (RORTY, 1992, p. 58). Da mesma forma, essas faculdades não conferem centralidade a um "eu" enquanto "razão", como na lógica da tradição cartesiana. Essa descentralidade do "eu" se resume na questão paradigmática que Rorty atribui a Freud, na sua afirmação de que "O ego não é o senhor dentro da sua própria casa" (FREUD, 1917/2006, p.153). Nesse sentido, o "eu" perde o estatuto de conjunto único de crenças e desejos, mas é representado por uma rede causal descentralizada (AZEVEDO, 2007).

A partir de uma dimensão histórica é possível pensar o que nos constitui, não mais sob a ótica de verdades necessárias e essenciais, mas a partir de "contingências idiossincráticas cruciais do passado [a fim de] criar eus presentes que sejamos capazes de respeitar" (RORTY, 1992, p. 59). Nós nos envolvemos com nossas próprias metáforas, vivendo contínuas recriações de nós mesmos.

A partir do exposto, feitas algumas considerações sobre a abordagem deflacionista, traça-se um paralelo da teoria de Rorty com a obra de Freud. Apesar de não ser filósofo, Freud foi um pensador que influenciou amplamente diversos campos do conhecimento, constantemente em franco diálogo com temáticas caras à filosofia.

\section{Freud e a questão da realidade}

Ao longo de seus escritos, Freud moldou um corpo teórico que, em sucessivas etapas, foi ganhando novos contornos. O que é conhecido hoje como psicanálise vem sendo construído desde o final do século XIX, com os primeiros contatos de Freud com as ciências naturais e a sua experiência clínica ainda na condição de neurologista. Em uma de suas obras iniciais de grande importância e complexidade, o Projeto para uma Psicologia Científica, escrita em 1895, e publicada somente em 
1950, Freud se dedica a temas como a percepção, a memória, a experiência de satisfação e dor, a consciência, os sonhos e a realidade construída pelo sujeito e pelo outro da linguagem, ou seja, o encontro com a alteridade.

Em Projeto, Freud levanta hipóteses sobre o "aparelho psíquico", referindo-se ao funcionamento dos neurônios (modelo de excitação neuronal) e ao fluxo de energia no sistema nervoso. A partir de três sistemas ele constrói o aparelho (ou aparato) (GARCIA-ROZA, 2008). Os sistemas que compõem o aparelho, de acordo com Freud são: $\varphi$, que capta a quantidade de energia (Q) fluente, por meio dos órgãos dos sentidos e que, por sua vez, penetra nos neurônios. O fluxo é propagado para o sistema $\Psi$, que não tem contato com o mundo externo, mas se restringe à captação dos estímulos de $\varphi$ e de elementos celulares no interior do corpo. Enquanto o sistema $\varphi$ trabalha com a percepção, o sistema $\Psi$ é responsável pela memória das alterações nos estados neuronais. Um terceiro sistema, $\omega$, é responsável pela percepção-consciência e irá operar as sensações, ao receber a estimulação do sistema $\Psi$.

Em relação às fontes de estimulação sobre as quais nos fala Freud, o organismo reage de modo distinto. O mundo externo, para ele, "constitui a fonte de todas as grandes quantidades de energia" (FREUD, 1895/2006, p. 356), e a estimulação recebida é descarregada pelas vias motoras. Já a estimulação endógena, que cria as grandes necessidades, como fome, respiração e sexualidade, não pode ser evitada. A condição para a descarga de estímulos endógenos é mais complexa e, segundo Freud, depende de condições do mundo externo, sendo configurada no que ele denomina de ação específica, efetuada por "ajuda alheia, quando a atenção de uma pessoa experiente é voltada para um estado infantil" (FREUD, 1895/2006, p. 370).

Freud assinala a ação do outro sobre o humano, na infância, como condição para a diminuição da estimulação, atrelando-a à consequente "experiência de satisfação". A ação específica nos ajuda a compreender de que forma cada um se relaciona com a realidade externa. A intervenção de um outro, a "ajuda alheia", significa uma mudança no mundo externo (como o fornecimento de suprimentos, a aproximação com o objeto sexual), acarretando constantes transformações na vida psíquica. Essa intervenção da alteridade, não somente satisfaz a necessidade do humano, mas o introduz em uma ordem simbólica. O apelo feito pela criança, 
através do choro, é lido como "signos de uma demanda, demanda ao outro" (GARCIA-ROZA, 2008, p. 133).

A "experiência de satisfação", tal como concebida por Freud nesse momento de sua obra, ocasionará a eliminação do impulso que outrora causara desprazer e, no sistema $\Psi$, a ativação de imagens mnêmicas do objeto com o qual se obteve satisfação. Quando um estado de urgência ou de desejo, como diz Freud, se repetir, haverá uma reativação das lembranças, "neste caso, deixa de ocorrer a satisfação, porque o objeto não é real, mas está presente apenas como ideia imaginária" (FREUD, 1895/2006, p. 377).

Se não há objeto real, portanto, não se produzindo satisfação, não há percepção desse objeto, mas uma alucinação dele. A consequência inevitável, segundo Freud, é o desapontamento. Daí deriva, como afirma Garcia-Roza (2008, p. 154), "a necessidade de se distinguir entre a imagem percepção e a imagemlembrança. Essa é a função do princípio de realidade".

A partir desses processos é ditada a relação do sujeito com a realidade. É ao sistema $\omega$ que Freud atribui um funcionamento através de excitação qualitativa e não de quantidade $(Q)$, é ele o responsável pela consciência, pelas sensações conscientes (diferentemente dos sistemas $\varphi$ e $\Psi$, que regem processos inconscientes). Nesse caso, "a descarga proveniente de $\omega$ constitui a indicação da qualidade ou da realidade para $\Psi "$ (FREUD, 1895/2006, p. 378).

A realidade externa é traduzida através de sinais sensoriais pelo sistema da consciência, que é concebida como "o lado subjetivo de uma parte dos processos físicos do sistema nervoso, isto é, dos processos w" (FREUD, 1895/2006, p. 363). O que Freud chama de qualidade é exatamente aquilo que não é redutível à quantificação, à mensuração.

No Projeto, Freud faz, pela primeira vez, a distinção entre "realidade externa" e "realidade do pensamento" (FREUD, 1895/2006, p. 428). Para a primeira, termos equivalentes são encontrados na obra freudiana na tradução em português: "realidade factual", "efetiva", "histórica" ou "material". Sobre o pensar, Freud afirma: "quando uma vez concluído o ato de pensamento, a indicação da realidade chega à percepção, obtém-se então um juízo de realidade, uma crença, atingindo-se com isso o objetivo de toda a atividade" (FREUD, 1895/2006, p. 385). 
Desse modo, a realidade que se apresenta em indicadores, em signos, é sempre processada e percebida, pois os signos são submetidos à estrutura da linguagem. A realidade, em última instância, se configura em uma crença. Sob a perspectiva, portanto, da psicanálise, segundo Garcia-Roza (2008, p. 165), "a realidade, ou, para ser mais exato, o real, nunca é dado. Um juízo de existência tem sempre o estatuto de uma hipótese".

\section{Realidade psíquica: verdade do sujeito?}

Com a Interpretação dos Sonhos, publicado em 1900, na virada para o novo século, Freud imprime um marco importante na sua teoria, no que tange à problemática da "realidade de pensamento", ao adotar a denominação "realidade psíquica" [psychische Realität]. Nesta obra, Freud toma os sonhos como material de análise, dando pistas de como o sujeito, imerso no sonho, tece sua relação com a realidade. Ele retoma a ideia do Projeto, de alucinação do objeto, ao dizer que os sonhos alucinam, ou seja, que nós transformamos o pensamento em alucinações oníricas, vivendo uma experiência de completa crença nas alucinações. A realidade dos sonhos não é uma mera representação do mundo externo, mas uma produção subjetiva no momento do sono. Há uma condição primordial humana, que configura a apreensão da realidade: a procura do sujeito pelo objeto de desejo. Essa realidade, inicialmente precária "enquanto sustentada pelo desejo, é, de início, alucinada" (AZZI, 2007, p. 248).

Ainda na Interpretação dos Sonhos, Freud atenta para o fato de que tradicionalmente o termo "psíquico" era confundido com "consciente", e que sua teoria abarca principalmente os processos psíquicos inconscientes. No caso dos sonhos, por exemplo, sendo produtos, manifestações do inconsciente, a consciência não dispõe de meios que separem uma realidade objetiva das imagens oníricas. Trata-se de um fenômeno inconsciente. No capítulo VII desta obra, é traçada a primeira tópica freudiana (Inconsciente - Pré-Consciente - Consciência), redesenhando a antiga concepção de aparelho psíquico. Segundo Freud (1900/2006, p. 637):

O inconsciente é a verdadeira realidade psíquica [...] ele nos é tão desconhecido quanto a realidade do mundo externo, e é tão

Cad. de Pesq. Interdisc. em Ci-s. Hum-s. Florianópolis, Santa Catarina, Brasil, ISSN 1984-8951 v.14, n.105, p.50-64, ago/dez 2013 
incompletamente apresentado pelos dados da consciência quanto o é o mundo externo pelas comunicações de nossos órgãos sensoriais.

A realidade psíquica é entendida, portanto, como um aspecto da singularidade humana. Ela é psíquica, pois não há possibilidade de atingirmos o mundo real, a não ser pela via da linguagem, na qual somos introduzidos desde a primeira infância, tal como proposto pro Freud no Projeto. A psicanálise demonstra que a relação do sujeito com a realidade não deixa de ser "efeito da forma como esse sujeito se articula no laço social, ou seja, do modo como ele se dirige ao Outro, efeito, portanto, da forma como esta alteridade se apresenta a ele" (AZZI, 2007, p. 247). Essa realidade psíquica, articulada pelo inconsciente "necessariamente linguístico" (RORTY, 1999, p. 200), isto é, pelo desejo e pelas fantasias do sujeito, é tão real quanto o que ele capta do seu entorno. É dela que a clínica psicanalítica, inventada por Freud, se ocupa, através da fala dos analisantes.

Posteriormente ao Projeto, Freud formula uma teorização sobre 0 inconsciente. Em correspondência ao amigo Wilhelm Fliess, a Carta 69, de 1897, ele afirma que "no inconsciente, não há indicações de realidade, de modo que não se consegue distinguir entre a verdade e a ficção que é catexizada com o afeto" (FREUD, 1897/2006, p. 310). Nesse sentido, a verdade é a própria ficção do sujeito, a rememoração de vivências que tece a realidade psíquica. Em um trecho de $A$ Psicopatologia da Vida Cotidiana, Freud sugere que a realidade, atravessada pela percepção é distorcida. Em um tom jocoso, ele diz:

Só aos espíritos mais seletos e equilibrados parece ser possível preservar a imagem da realidade externa, tal como percebida, da distorção a que ela costuma ficar sujeita em sua passagem pela individualidade psíquica daquele que a percebe (FREUD, 1901/2006, p. 228).

O problema da realidade ainda é desenvolvido mais adiante por Freud, ao confrontar as formas com que ela se manifesta: "a realidade psíquica é uma forma especial de existência que não deve ser confundida com a realidade material" (FREUD, 1900/2006, p. 644). Fazendo uma distinção entre as duas, Freud não busca polarizá-las ou pô-las em oposição binária. A todo tempo parece haver um limite tênue entre as duas realidades. Versiani (2001, p. 131) alude à implicação que a temática da realidade tem na psicanálise, através da questão: "Faz diferença se o que o paciente me relata aconteceu de fato ou não?". Ela propõe uma reflexão no 
sentido de que realidade material e realidade psíquica não se excluem, nem tampouco de que essa aparente dualidade seja uma indecisão da parte de Freud. As duas realidades estão conjugadas, no que esta autora chama de "realidade-orapsíquica-ora-material".

Em um momento importante de transição da sua teoria, por volta de 1914, Freud passa a considerar a "importância das fantasias na constituição das neuroses" (VERSIANI, 2001, p. 132), apontando para a perspectiva da verdade construída pelo sujeito. Nesse sentido, não importa tanto se, por exemplo, no âmbito da clínica, o paciente está se recordando de algo que ocorreu ou se o que está trazendo à tona diz respeito a suas fantasias.

Posteriormente, Freud, nas Conferências Introdutórias sobre Psicanálise, referindo-se à formação dos sintomas na neurose, enuncia:

[...] as experiências da infância, construídas ou recordadas na análise são, às vezes, indiscutivelmente falsas $e$, às vezes, por igual, certamente corretas, e na maior parte dos casos são situações compostas de verdade e de falsificação" (FREUD, 1915-1916/2006, p. 369).

Essa questão, do acontecer ou não, não retira da experiência singular do sujeito seu estatuto de verdade. O desdobramento disso é que, em última instância, a realidade é psíquica, pois se configura de modo singular para o sujeito, e isto inclui a realidade material, o que significa que a realidade psíquica não pode ser compreendida por si só. Não há, então, verdade revelada do exterior, mas verdade do sujeito e seu desejo, na sua dimensão idiossincrática, ao mesmo tempo familiar e estranha.

\section{Considerações finais}

É por meio de uma noção de estranhamento, de destituição de verdade absoluta que nos aproximamos dessa noção de realidade e de suas implicações na subjetividade. O sujeito, para a psicanálise, não é o indivíduo que detém a verdade, e que possuiria um conhecimento pleno de si. Tampouco o aparelho psíquico do qual nos falava Freud tem a função de refletir a realidade. Esse sujeito, aqui "desessencializado", não é mais um núcleo fixo, não coincide consigo mesmo 
(VIDAL, 2008). Do contrário, ele é multiplicidade, resultado de convergências, o tecido entranhado das contingências singulares, tal como propõe Rorty.

É a partir de Rorty que podemos ler Freud pela ótica da contingência. $O$ pensamento rortyano destaca o direcionamento de Freud que nos confere a "capacidade para nos desviar do universal para o concreto, da tentativa de encontrar verdades necessárias e crenças inabaláveis para as contingências idiossincráticas dos nossos passados individuais" (RORTY, 1992, p. 60). Imerso em uma ordem de linguagem, o humano perde a sua "natureza intrínseca", e, portanto, a suposta essência. De acordo com Rorty (1992) é o próprio Freud quem desvincula a humanidade da noção de espécie natural, plena de poderes essenciais a desenvolver. O que partilhamos como humanos é a faculdade de criar metáforas e nos reinventarmos, nos redescrevermos a partir do que há de singular em nossas fantasias idiossincráticas.

Tanto Rorty quanto Freud contribuem para um ultrapassamento do modelo cartesiano sobre o sujeito do conhecimento, capaz de se depurar do que há em si de mais humano - dúvidas, paixões, imaginação, etc. - e de se separar do seu objeto de estudo, de modo neutro, impessoal. A “abertura epistemológica”, proposta pelos autores aqui mencionados, propicia uma implicação subjetiva no processo de produção do conhecimento, ressaltando que as contingências idiossincráticas não devem ser excluídas. Nesse sentido, não se trata de apreender os dados da realidade como verdade única, mas produzi-lo a partir da dimensão de singularidade.

Esses são alguns dos principais pontos de contato entre as formulações de Rorty e Freud, pensadores que nos inspiram a pensar sobre a contemporaneidade e as nuances da subjetividade. Entre verdade e realidade, dialogam psicanálise e filosofia, abrindo espaços para o entrelace de saberes e suas constantes reatualizações. 


\section{Referências}

AZZI, I. C. S. Realidade: uma razão que não se explica, mas se crê. Ágora: Estudos em Teoria Psicanalítica, v. 10, n. 2, p. 245-263. 2007.

AZEVEDO, F. M. T. de. Freud e a Reflexão Moral - A Questão da Contingência do Indivíduo em Richard Rorty. Análogos, v. 7, n. 1, p.132-140. 2007.

D'AGORD, M. R. de L.; BINKOWSKI, G. I.; CHITTONI, F. B. Psicanálise e pragmatismo: aproximações e possibilidades. Psicologia em Revista, v. 14, n. 1, p. 47-62. 2008.

DESCARTES, R. Discurso do método (1637). São Paulo: Parma, 1983.

FREUD, S. Projeto para uma Psicologia Científica (1895). In: Edição Standard Brasileira das Obras Psicológicas Completas de Sigmund Freud. v.1. Rio de Janeiro: Imago, 2006.

FREUD, S. Extratos dos documentos dirigidos a Fliess (1897). In: Edição Standard Brasileira das Obras Psicológicas Completas de Sigmund Freud. v.1. Rio de Janeiro: Imago, 2006.

FREUD, S. A Interpretação dos Sonhos (1900). In: Edição Standard Brasileira das Obras Psicológicas Completas de Sigmund Freud. v. 4 e 5 . Rio de Janeiro: Imago, 2006.

FREUD, S. Sobre a Psicopatologia da Vida Cotidiana (1901). In: Edição Standard Brasileira das Obras Psicológicas Completas de Sigmund Freud. v. 6. Rio de Janeiro: Imago, 2006.

FREUD, S. Conferências Introdutórias Sobre Psicanálise (Parte III). (1915-1916). In: Edição Standard Brasileira das Obras Psicológicas Completas de Sigmund Freud. v. 16. Rio de Janeiro: Imago, 2006.

FREUD, S. Uma dificuldade no caminho da psicanálise (1917). In: Edição Standard Brasileira das Obras Psicológicas Completas de Sigmund Freud. v. 16. Rio de Janeiro: Imago, 2006. 
GARCIA-ROZA, L. A. Introdução à Metapsicologia Freudiana 1. Sobre as afasias: O projeto de 1895. Rio de Janeiro: Jorge Zahar, 2008.

GHIRALDELLI JÚNIOR, P. O que há de real e de irreal com o realismo: Searle versus Rorty. Trans/Form/Ação, Marília, v. 21-22, n.1, p. 119-129. 1999.

PINTO, P. R. M. Richard Rorty, arauto de uma nova visão de mundo. Kriterion, Belo Horizonte, v. 48, n.116, p. 527-531. 2007.

POGREBINSCHI, T. Será o neopragmatismo pragmatista? Interpelando Richard Rorty. Novos estud. - CEBRAP, São Paulo, n. 74, p. 125-138. 2006.

RORTY, R. Contingência, ironia e solidariedade. Tradução Nuno Ferreira da Fonseca. Lisboa: Editorial Presença, 1992.

RORTY, R. Ensaios sobre Heidegger e outros. Rio de Janeiro: Relume-Dumará, 1999.

VERSIANI, E. R. A realidade "ora-psíquica-ora-material" em Freud. Ágora: Estudos em Teoria Psicanalítica, Rio de Janeiro, v. 4, n.1, p.131-144. 2001.

VIDAL, P. E. V. A máquina do psiquismo. Estudos de Psicologia, Natal, v.13, n. 3, p. 267-273. 2008.

Artigo:

Recebido em: 31/08/2013

Aceito em: 06/12/2013 